\title{
Neonatal sepsis and associated factors among newborns in hospitals of Wolaita Sodo Town, Southern Ethiopia
}

This article was published in the following Dove Medical Press journal: Research and Reports in Neonatology

\author{
Abera Mersha \\ Tilahun Worku \\ Shitaye Shibiru \\ Agegnehu Bante \\ Addis Molla \\ Genzeb Seifu \\ Girma Huka \\ Eyerusalem Abrham \\ Temesgen Teshome \\ Department of Nursing, College of \\ Medicine and Health Sciences, Arba \\ Minch University, Arba Minch, Ethiopia
}

Correspondence: Abera Mersha Department of Nursing, College of Medicine and Health Sciences, Arba Minch University, PO Box 2I, Arba Minch, Ethiopia

Tel $+25|9| 0389538$

Fax $+25|96| 4 \mid 3332$

Email mershaabera@gmail.com
Introduction: Neonatal sepsis is one of the most common reasons for admission to neonatal intensive care units in developing countries. It is also a major cause of mortality in both developed and developing countries. Hence, the main aim of this study was to assess the prevalence and factors associated with neonatal sepsis among newborns in hospitals of Wolaita Sodo Town, Southern Ethiopia.

Materials and methods: This hospital-based cross-sectional study was conducted in 275 newborns from April 22 to June 29, 2018. Structured interviewer-administered pre-tested questionnaire and check list were used to collect the data. The collected data were entered into Epi data version 3.1 and then exported into SPSS Windows version 22 for analysis. Bivariate and multivariate analyses were done by using binary logistic regression. The goodness of fit was tested by Hosmer-Lemeshow statistic and Omnibus tests. Multi-co-linearity test was carried out to determine the correlation between independent variables by using standard error and collinearity statistics. Variables with $P<0.25$ in the bivariate analysis were included in the final model, and statistical significance was declared at $P<0.05$.

Results: This study found that $33.8 \%$ (95\% CI: $28 \%-39 \%$ ) of the neonates had neonatal sepsis during admission. Factors such as maternal age, multiple per digital vaginal examination, exclusive and immediate breastfeeding within an hour, put on kangaroo mother care (KMC) within 1 hour, and neonatal age were statistically significantly associated with neonatal sepsis. Conclusion and recommendations: This study indicated that the current rate of neonatal sepsis was still high. As such, strengthening the provision of health information on exclusive and immediate breastfeeding and $\mathrm{KMC}$ on postnatal and antenatal care services and decrease multiple per digital vaginal examination as not indicated should better to be promoted.

Keywords: neonatal sepsis, sepsis neonatorum, neonatal infection, neonatal intensive care unit, safe delivery, Ethiopia

\section{Introduction}

Neonatal sepsis is a condition defined as a clinical syndrome characterized by signs and symptoms of infection in an infant 28 days of life or younger. This manifested by systemic signs of infection and isolation of a bacterial or other pathogen from the bloodstream $^{1}$ results in an estimated 750,000 annual deaths worldwide., ${ }^{2,3}$ Globally, sepsis is still one of the major causes of morbidity and mortality in neonates, despite recent advances in healthcare units. The estimated global burden for neonatal sepsis was 2,202 (95\% CI: 1,099-4,360) per 100,000 live births, with mortality between 11\% and $19 \% .{ }^{4,5}$ More than $40 \%$ of under-five deaths occur in the neonatal period, resulting in 3.1 million newborn deaths each year. ${ }^{6}$ 
According to the Global Sepsis Alliance, infections leading to sepsis are responsible for about one-fifth of the world's annual 2.7 million neonatal deaths, and in South Asia and sub-Saharan Africa, it was about $25 \%$ of all neonatal deaths. ${ }^{?}$ Incidence of neonatal sepsis is around 40 times higher and mortality rates are two times higher in middle-income countries than in high-income countries. ${ }^{4}$ Neonatal sepsis poses a massive public health burden for sub-Saharan Africa, with significant associated economic consequences. ${ }^{8}$ On the other hand, the survivors of neonatal sepsis are vulnerable to shortand long-term neurodevelopment morbidity. ${ }^{9}$

Neonatal sepsis is the major newborn killer in Ethiopia, which accounts for more than one-third (33\%) of neonatal deaths. ${ }^{10,11}$ The Ethiopian population grows at a rate of $2.6 \%$ per annum and the majority of people (84\%) reside in rural areas. ${ }^{12,13}$ According to the 2016 Ethiopia Demographic and Health Surveys, neonatal mortality declined from 49 deaths per 1,000 live births in 2000 to 29 deaths per 1,000 births in 2016, a reduction of $41 \%$ over the past 16 years. ${ }^{14}$ Although the causes of neonatal mortality are not well documented in Ethiopia, reports from a previous study identified neonatal sepsis, asphyxia, birth injury, tetanus, preterm birth, congenital malformations, and "unknown causes" as major reasons for neonatal mortality. ${ }^{12}$ Evidence from different studies conducted in different countries speculated that neonates who were diagnosed with suspected sepsis ranged from $4.3 \%$ to $75.1 \%$ among the neonates admitted to the neonatal intensive care units (NICUs). ${ }^{15-22}$

Despite advancing healthcare system in Ethiopia, the admission of neonates to the NICU with infection, most typically sepsis, has been increased. But, there is limited study in Ethiopia, in study area that shows the recent status of neonatal sepsis and the affecting factors. Hence, this study was aimed at studying the prevalence of neonatal sepsis and factors affecting among newborns in hospitals of Wolaita Sodo, Southern Ethiopia.

\section{Materials and methods Study setting and period}

This study was performed in hospitals of Wolaita Sodo from April 22 to June 29, 2018. Wolaita Sodo is one of the towns in South Nations, Nationalities and Peoples' Region (SNNPR) of Ethiopia, and it is located $411 \mathrm{~km}$ from Addis Ababa, the capital city of Ethiopia, and $156 \mathrm{~km}$ from Hawassa, the regional town of SNNPR. Based on the 2018 Population Projection by the Central Statistical Agency, this town has a total population of 254,294, of whom 125,855 are men and 128,439 are women. The town has two hospitals Soddo Christian Hospital and Wolaita Sodo University Teaching Referral Hospital. Currently, Sodo is known for being the center of major health and education institutions in Ethiopia. Soddo Christian Hospital has been one of the ten surgical training centers in Africa. The hospital provides a full range of medical and surgical service, including orthopedic and general, maternity, and pediatrics. Wolaita Sodo University Teaching Referral Hospital is also located in this town and serves around 2 million people.

\section{Study design}

An institution (hospital)-based cross-sectional study design was employed.

\section{Population}

All neonates who were admitted to NICU of hospitals during the study period in Wolaita Sodo were the study population for this study.

\section{Eligibility criteria}

All neonates who were admitted to intensive care unit were included in this study, whereas neonates who were early discharged before data collection was completed but only card was available, incomplete patient chart information, and died on arrival (neonates expired without taking any investigation and treatment on arrival) were excluded from this study.

\section{Sample size determination}

Epi info7 software Stat Cal was used to calculate the sample sizes. To determine the prevalence of neonatal sepsis single population proportion and to identify the associated factors, two sample population proportion was used. The sample used for this study was 275 , after adding non-response rate of $5 \%$ to the larger sample size which was 261.

\section{Data collection methods}

A pre-tested interviewer-administered questionnaire and check lists were used to collect the data. The tools were developed by reviewing different literatures. The information was collected during the admission of neonate to NICU and by reviewing the registration book records in labor ward, NICU, and gynecologic ward in each hospital.

\section{Study variables}

The prevalence of neonatal sepsis was the dependent variable, and sociodemographic characteristics of mothers, sociodemographic characteristics of neonates, and obstetric characteristics of mothers were independent variables for this study. 


\section{Data quality control}

We followed the methods of Mersha ${ }^{23}$ and to ensure quality of data, the questionnaire and checklists were initially drafted in English, and then translated into a local language, "Amharic" by verified translators. Lastly, before data collection, the questionnaire was back translated into English to ensure accuracy. The tools were pre-tested in hospital with similar status. Data were checked for completeness, accuracy, clarity, and consistency before being entered into software. Proper coding and categorization of data were maintained for the quality of the data to be analyzed. Double data entry was used to ensure validity and compared with the original data. ${ }^{23}$

\section{Data management and analysis}

The collected data were coded and entered into Epi data version 3.1 in order to minimize logical errors and skipping patterns. Then, the data were exported to SPSS Windows version 22 for cleaning, editing, and analysis. Descriptive analysis was done by computing proportions and summary statistics. Then the information was presented by using simple frequencies, summary measures, tables, and figures. Bivariate and multivariate analyses were used to assess the association between each independent variable and the outcome variable by using binary logistic regression. Hosmer-Lemeshow statistic and Omnibus tests were conducted for model fitness. All variables with $P<0.25$ in the bivariate analysis were included in the final model of multivariate analysis in order to control all possible confounders. We followed the methods of Mersha ${ }^{23}$ that variables which were significant in previous studies and from context point of view were included in the final model even if the above criteria were not meet. Collinearity statistics was carried out to determine the correlation between the independent variables. The direction and strength of statistical association were measured by the OR with $95 \%$ CI. Adjusted OR along with $95 \%$ CI was estimated to identify the associated factors for neonatal sepsis. In this study, $P$-value $<0.05$ was considered to declare a result as a statistically significant association.

\section{Ethical considerations}

This study followed the principles of research ethics adopted by the 64th WMA General Assembly, Fortaleza, Brazil, October $2013^{24}$ and amendments including approval by the Institutional Review Board (AMU-IRB) of College of Medicine and Health Sciences, Arba Minch University. All study participants were informed about the purpose of the study, their right to refuse participation, and written and signed voluntary consent was obtained from all study participants prior to the interview. The respondents were also informed that the information obtained from them would be treated with utmost confidentiality.

\section{Results}

\section{Sociodemographic characteristics of the mothers}

A total of 275 neonates were involved in this study with a response rate of $100 \%$. The mean age of mothers of the neonates were 27.39 years ( $\pm 6.51 \mathrm{SD})$. Of the respondents, married respondents constitute 199 (72.4\%) and those lived in rural locations comprise $172(62.5 \%)$. Protestant was the dominant religion (165 [60\%]) (Table 1).

Table I Sociodemographic characteristics of mothers in hospitals of Wolaita Sodo, Southern Ethiopia, $2018(n=275)$

\begin{tabular}{|c|c|c|}
\hline Variables & Frequency & Percentage \\
\hline \multicolumn{3}{|l|}{ Age, years } \\
\hline$<20$ & 22 & 8 \\
\hline $20-34$ & 176 & 64 \\
\hline $35-49$ & 77 & 28 \\
\hline \multicolumn{3}{|l|}{ Marital status } \\
\hline Single & 4 & 1.5 \\
\hline Married & 199 & 72.4 \\
\hline Cohabited & 8 & 2.9 \\
\hline Separated due to work & 42 & 15.3 \\
\hline Divorced & 18 & 6.5 \\
\hline Widowed & 4 & 1.5 \\
\hline \multicolumn{3}{|l|}{ Religion } \\
\hline Orthodox & 72 & 26.2 \\
\hline Protestant & 165 & 60 \\
\hline Muslim & 15 & 5.5 \\
\hline Catholic & 17 & 6.2 \\
\hline Traditional & 6 & 2.2 \\
\hline \multicolumn{3}{|l|}{ Educational status } \\
\hline Cannot read and write & 20 & 7.3 \\
\hline Read and write & 19 & 6.9 \\
\hline Grade I-8 & 33 & 12 \\
\hline Grade 9-12 & 128 & 46.5 \\
\hline College and above & 75 & 27.3 \\
\hline \multicolumn{3}{|l|}{ Occupation } \\
\hline Governmental employee & 17 & 6.2 \\
\hline Merchant & 83 & 30.2 \\
\hline Farmer & 117 & 42.5 \\
\hline Self-employee & 25 & 9.1 \\
\hline Housewife & 33 & 12 \\
\hline \multicolumn{3}{|l|}{ Family size } \\
\hline$<4$ & 138 & 50.2 \\
\hline $4-6$ & 137 & 49.8 \\
\hline \multicolumn{3}{|c|}{ Average income per month (Ethiopian Birr) } \\
\hline$<1,399$ & 92 & 33.5 \\
\hline I,400-1,999 & 46 & 16.7 \\
\hline $2,000-2,599$ & 46 & 16.7 \\
\hline$>2,600$ & 91 & 33.1 \\
\hline
\end{tabular}




\section{Obstetric characteristics of the mothers}

Of the total mothers of the neonates, 183 (66.5\%) were multipara and 229 (83.3\%) had antenatal care follow-up. One hundred thirty-eight $(60.3 \%)$ had one to three visit and 91 (39.7\%) had four visits. One hundred forty-one (51.3\%) of mothers gave birth with spontaneous vaginal delivery and 44 (16\%) and 90 (32.7\%) gave birth with instrument assisted and cesarean section, respectively. Regarding delivery assistant, 245 (89.1\%) of mothers were assisted by health professionals (physicians, health offer, midwifes, and nurses). During labor, $212(77.1 \%)$ mothers had $\leq 4$ digital vaginal examination and $92(33.5 \%)$ had foul smelling amniotic fluid. Seventyfive $(27.3 \%)$ of mothers had history of pregnancy-induced hypertension, 46 (16.7\%) had a urinary tract infection/sexu-

Table 2 Obstetric characteristics of mothers in hospitals of Wolaita Sodo, Southern Ethiopia, $2018(n=275)$

\begin{tabular}{|c|c|c|}
\hline Variables & Frequency & Percentage \\
\hline \multicolumn{3}{|l|}{ Delivery assistant } \\
\hline TTBA & 15 & 5.5 \\
\hline HEW & 6 & 2.2 \\
\hline Health professional & 245 & 89.1 \\
\hline Relatives & 9 & 3.3 \\
\hline \multicolumn{3}{|c|}{ Digital vaginal examination } \\
\hline$\leq 4$ times & 212 & 77.1 \\
\hline$>4$ times & 63 & 22.9 \\
\hline \multicolumn{3}{|c|}{ Foul smelling amniotic fluid } \\
\hline Yes & 92 & 33.5 \\
\hline No & 183 & 66.5 \\
\hline \multicolumn{3}{|c|}{ Pregnancy-induced hypertension } \\
\hline Yes & 75 & 27.3 \\
\hline No & 200 & 72.7 \\
\hline \multicolumn{3}{|c|}{ Bleeding during pregnancy/APH } \\
\hline Yes & 19 & 6.9 \\
\hline No & 256 & 93.1 \\
\hline \multicolumn{3}{|l|}{ UTI/STI } \\
\hline Yes & 46 & 16.7 \\
\hline No & 229 & 83.3 \\
\hline \multicolumn{3}{|c|}{ Meconium-stained amniotic fluid } \\
\hline Yes & 17 & 6.2 \\
\hline No & 258 & 93.8 \\
\hline \multicolumn{3}{|c|}{ History of foul smelling liquor } \\
\hline Yes & 46 & 16.7 \\
\hline No & 229 & 83.3 \\
\hline \multicolumn{3}{|c|}{ History of chorioamionitis } \\
\hline Yes & 41 & 14.9 \\
\hline No & 234 & 85.1 \\
\hline \multicolumn{3}{|l|}{ PROM } \\
\hline Yes & 46 & 16.7 \\
\hline No & 229 & 83.3 \\
\hline \multicolumn{3}{|l|}{ Duration of PROM } \\
\hline$<18$ hours & 27 & 58.7 \\
\hline$\geq 18$ hours & 19 & 41.3 \\
\hline
\end{tabular}

Abbreviations: APH, antepartum haemorrhage; HEW, health extension worker; PROM, premature rupture of membrane; STI, sexually transmitted infection; TTBA, trained traditional birth attendant ; UTI, urinary tract infection. ally transmitted infection, and $41(14.9 \%)$ had a history of chorioamionitis (Table 2).

Two hundred five $(74.5 \%)$ neonates were delivered at hospital and $2.5 \%$ had at health post. For $36.7 \%$ of the mothers, the duration of labor was 12-24 hours and for the $16.7 \%$ it was $<6$ hours (Figures 1 and 2).

\section{Neonatal characteristics}

More than half (61.5\%) of the neonates were male and 183 (66.5\%) were in the age group $0-7$ days (early neonatal period) and the rest $92(33.5 \%)$ were from 8 to 28 days (late neonatal period). Regarding gestational age, 196 (71.3\%) had term (37-42 weeks), and 69 (25.1\%) and 10 (3.6\%) had preterm ( $<37$ weeks) and postterm ( $>42$ weeks), respectively. Majority of the neonates (88.4\%) had Apgar score of $\geq 7$, and 199 (72.4\%) were macrosomia or weight at birth $\geq 4 \mathrm{~kg}$. Two hundred nine (76\%) of the neonates cried at birth and $92(33.5 \%)$ of the neonates had resuscitated at birth. Nearly half (50.2\%) had gavage feeding and 229 (83.3\%) had been put on kangaroo mother care (KMC) within 1 hour after delivery (Table 3).

\section{Prevalence of neonatal sepsis}

Of the total study participants, $26.9 \%$ (95\% CI: $22 \%-32 \%$ ) of the neonates had early onset of neonatal sepsis and $6.9 \%$ (95\% CI: $4 \%-10 \%$ ) of the neonates had late onset of neonatal sepsis. Overall, in this study $33.8 \%$ (95\% CI: $28 \%-39 \%$ ) neonates had neonatal sepsis.

\section{Factors associated with neonatal sepsis}

After controlling for cofounders in the multivariate model maternal age, multiple per digital vaginal examination, exclusive and immediate breastfeeding within an hour, put on KMC within 1 hour of delivery, and age of the neonate were significantly associated with neonatal sepsis. However, place of delivery, urinary tract infection/sexually transmitted infection of the mother, premature rupture of membrane (PROM), neonate cried at birth, and Apgar scores were not. Neonates of the mothers aged 20-34 years were 33\% more likely to develop neonatal sepsis compared with age group $<20$ years, whereas digital vaginal examination $\leq 4$ times were $90 \%$ less likely to develop neonatal sepsis compared with more frequent vaginal examination. Neonates who had exclusive and immediate breastfeeding within an hour were $86 \%$ and those who had been put on $\mathrm{KMC}$ within 1 hour were $94 \%$ less likely to acquire sepsis. Those neonates whose age ranged from 0 to 7 days were two times more likely to develop sepsis as compared to those whose age ranged from 8 to 28 days (adjusted $\mathrm{OR}=2.19,95 \% \mathrm{CI}$ : 1.01-4.79) (Table 4). 


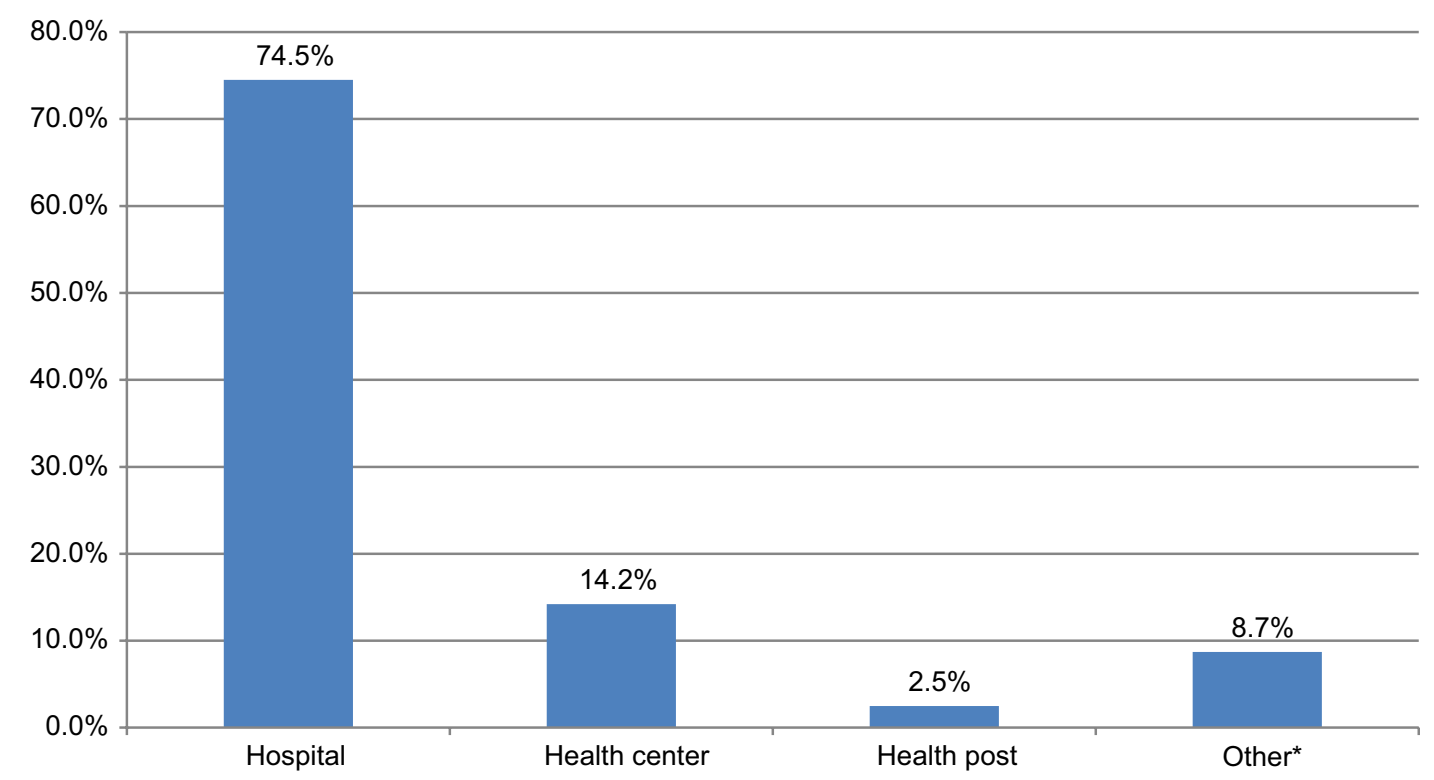

Figure I Place of delivery among mothers in hospitals of Wolaita Sodo, Southern Ethiopia, 2018 ( $n=275)$. Note: *Home delivery and on the way to health facility.

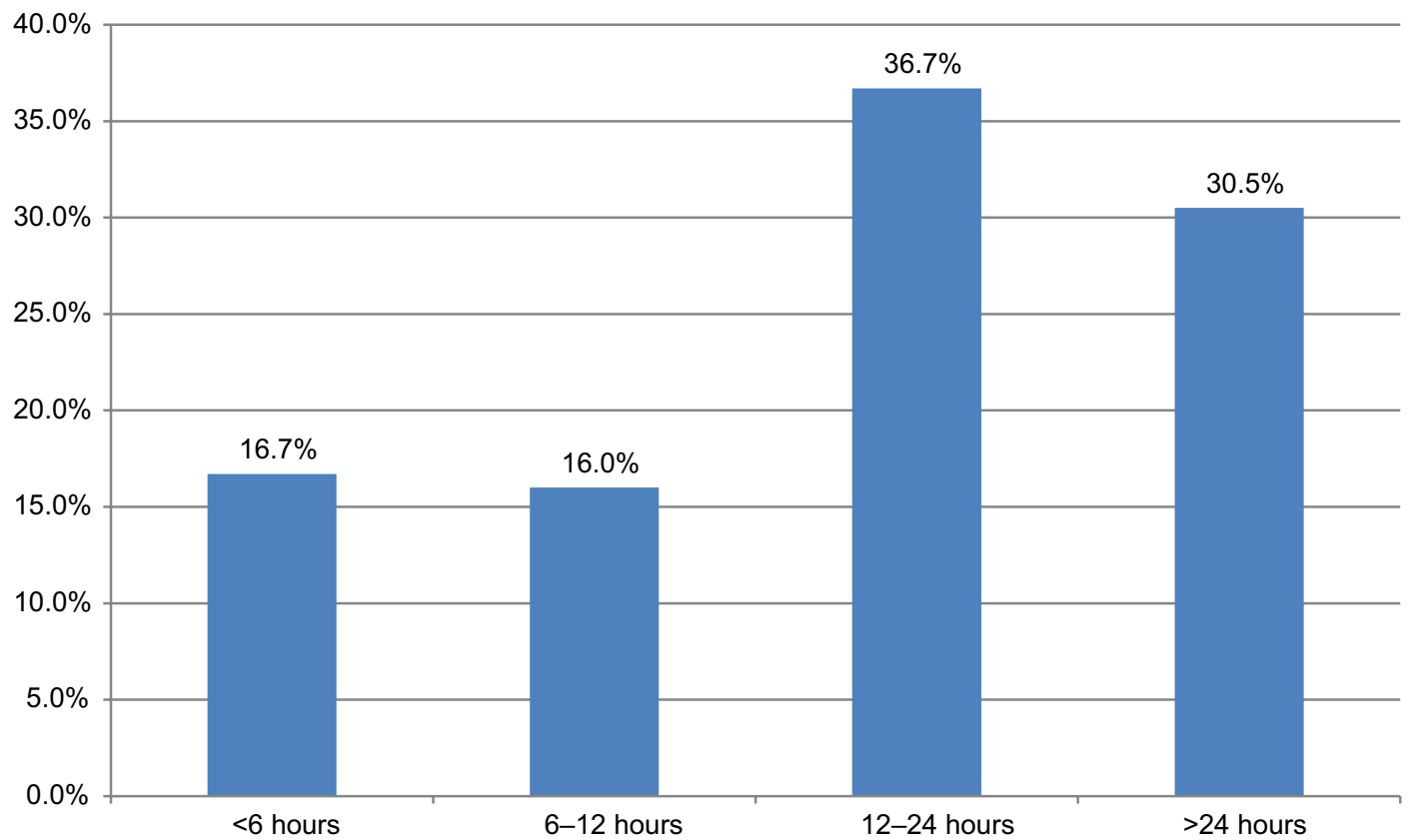

Figure 2 Duration of labor among mothers in hospitals of Wolaita Sodo, Southern Ethiopia, $2018(n=275)$.

\section{Discussion}

The overall status of neonatal sepsis was $33.8 \%$ (95\% CI: $28 \%-39 \%$ ). Maternal age of 20-34 years was 4.33 times whereas neonatal age of $0-7$ days was 2.19 times more likely to have sepsis or positively associated with neonatal sepsis. Those neonates from mothers with less frequent digital vaginal examinations ( $\leq 4$ times), exclusive and immediate breastfeeding within 1 hour, and put on $\mathrm{KMC}$ within 1 hour were negatively associated (preventive) with neonatal sepsis with odds $0.1,0.14$, and 0.06 , respectively.

The prevalence of neonatal sepsis in this study was lower compared with studies done in Egypt (45.9\%) and Ethiopia (75.1\%) and higher compared with the studies done at South Sinai, Egypt (8.6\%), Southern-Eastern Mexico (4.3\%), and Dar es Salaam, Tanzania (24\%). ${ }^{15-19}$ But, this finding was congruent with three studies done at Tanzania $(29 \%, 31.4 \%$, and 
$38.9 \%){ }^{20-22}$ The reason for this difference is due to advance in health system nowadays that gives infuses on newborn health start from intrauterine life (training of healthcare providers on infection prevention in delivery ward and NICU, safe delivery practice, basic emergency obstetric care, and comprehensive emergency obstetric care), increasing the health seeking behavior, and socioeconomic status of the community.

In this study, maternal-related factors were significantly associated with neonatal sepsis. Of this, maternal age and multiple per digital vaginal examination had risk factors that predispose the newborn for sepsis. This was in line with study done in Tanzania and Ghana. ${ }^{21,25}$ But, it was incongruent with study done at Northern Ethiopia. ${ }^{26}$ This may be due to methodological, difference in the healthcare delivery system, socioeconomic, and cultural factors.

As stated in this study, finding KMC (skin to skin contact) and immediate and exclusive breastfeeding within 1

Table 3 Neonatal characteristics in hospitals of Wolaita Sodo, Southern Ethiopia, $2018(n=275)$

\begin{tabular}{|c|c|c|}
\hline Variables & Frequency & Percentage \\
\hline \multicolumn{3}{|c|}{ Weight of the baby at birth } \\
\hline Macrosomia ( $\geq 4$ kg) & 16 & 5.8 \\
\hline Normal (2.5-4 kg) & 199 & 72.4 \\
\hline LBW (I.5-2.5 kg) & 60 & 21.8 \\
\hline \multicolumn{3}{|l|}{ Temperature $\left({ }^{\circ} \mathrm{C}\right)$} \\
\hline$<36.5$ & 80 & 29.1 \\
\hline $36.5-37.5$ & 154 & 56 \\
\hline$>37.5$ & 41 & 14.9 \\
\hline \multicolumn{3}{|c|}{ Neonate cries at birth } \\
\hline Yes & 209 & 76 \\
\hline No & 66 & 24 \\
\hline \multicolumn{3}{|l|}{ Prenatal asphyxia } \\
\hline Yes & 11 & 4 \\
\hline No & 264 & 96 \\
\hline \multicolumn{3}{|l|}{ Gavage feeding } \\
\hline Yes & 138 & 50.2 \\
\hline No & 137 & 49.8 \\
\hline \multicolumn{3}{|c|}{ Exclusive and immediate breastfeeding within I hour } \\
\hline Yes & 137 & 49.8 \\
\hline No & 138 & 50.2 \\
\hline \multicolumn{3}{|c|}{ Put on KMC within I hour } \\
\hline Yes & 229 & 83.3 \\
\hline No & 46 & 16.7 \\
\hline \multicolumn{3}{|c|}{ Ways of attachment arranged for KMC } \\
\hline Good & 183 & 79.9 \\
\hline Poor & 46 & 20.1 \\
\hline \multicolumn{3}{|c|}{ Resuscitated at birth } \\
\hline Yes & 92 & 33.5 \\
\hline No & 183 & 66.5 \\
\hline \multicolumn{3}{|c|}{ Meconium aspirated } \\
\hline Yes & 92 & 33.5 \\
\hline No & 183 & 66.5 \\
\hline
\end{tabular}

Abbreviations: KMC, kangaroo mother care; LBW, low birth weight. hour of delivery were significantly associated with neonatal sepsis. This finding was in line with study done in Zimbabwe, meta-analysis done by reviewing different literatures, and studies conducted in different parts of the world. ${ }^{27-30}$ The reason for this is due to the fact that $\mathrm{KMC}$ increases mother to baby bonding, breastfeeding, and thermal protection better than conventional care and gives less opportunity for infections. In addition, immediate and exclusive breastfeeding serves as the starting point for a continuum of care for mother and newborn who can have long-lasting effects on health and development. Early initiation of breastfeeding provides adequate nutrition at appropriate time, immunological value from first milk (colostrum), which prevents hypothermia and hypoglycemia. The age of neonate was other significant effect for the occurrence of neonatal sepsis as reported by this study. The main reasons for this may be most newborns who harbor different infections agents during intrauterine life, intra-partum, and immediately after delivery show sign and symptoms during early period (0-7 days). Neonates are very sensitive to different infection agents during early period related to weakened immunity as compared to adults.

In multivariate analysis, maternal urinary tract infection or sexually transmitted infection, Apgar score $<7$ at fifth minute, crying immediately after birth, prolonged rupture of membrane, and place of delivery were not significantly associated with neonatal sepsis. This finding was incongruent with study done in Ghana, Egypt, south-eastern Mexico, Northern Ethiopia, and Mwanza Tanzani. ${ }^{17,18,22,25,26,31}$ The result of these incongruences may be due to the fact that the newborns are more susceptible for hospital as well as community-acquired infections in favor of maternal and neonatal factors. In addition, those discrepancies may be study setting, sociocultural, socioeconomic, and study period differences.

The limitation of this study was that the data might be subjected to recollection bias. The study might not show cause-and-effect relationship because the study design was cross-sectional.

\section{Conclusion and recommendations}

This study indicated that the prevalence of neonatal sepsis was still high. In general, this study identified that maternal age, multiple per digital vaginal examination, exclusive and immediate breastfeeding within an hour of delivery, put on KMC within 1 hour, and age of the neonate were factors affecting or predispose for neonatal sepsis. Based on these we would like to provide the following recommendations: strengthening the provision of health information on exclusive and immediate 
Table 4 Bivariate and multivariate analyses of factors associated with neonatal sepsis in Chencha District, Southern Ethiopia, 2018 $(n=275)$

\begin{tabular}{|c|c|c|c|c|}
\hline \multirow[t]{2}{*}{ Variables } & \multicolumn{2}{|c|}{ Neonatal sepsis (\%) } & \multicolumn{2}{|l|}{$(95 \% \mathrm{Cl})$} \\
\hline & No & Yes & Crude OR & Adjusted OR \\
\hline \multicolumn{5}{|c|}{ Maternal age (years) } \\
\hline$<20$ & $12(54.5)$ & $10(45.5)$ & 1 & I \\
\hline $20-34$ & $112(63.6)$ & $64(36.4)$ & $0.69(0.28-1.68)$ & $4.33(1.01-18.52)^{*}$ \\
\hline $35-49$ & $58(75.3)$ & $19(24.7)$ & $0.39(0.15-1.05)$ & $3.09(0.66-14.49)$ \\
\hline \multicolumn{5}{|c|}{ Place of delivery } \\
\hline Health facility & $172(68.5)$ & $79(3 \mid .5)$ & $0.33(0.14-0.77)$ & $0.78(0.22-2.8 \mathrm{I})$ \\
\hline Other $^{\mathrm{a}}$ & $10(41.7)$ & $14(58.3)$ & $\mathrm{I}$ & $\mathrm{I}$ \\
\hline \multicolumn{5}{|c|}{ Digital vaginal examination } \\
\hline$\leq 4$ times & $|5|(7 \mid .2)$ & $6 \mathrm{I}(28.8)$ & $0.39(0.22-0.69)$ & $0.10(0.04-0.25)^{* * *}$ \\
\hline$>4$ times & $31(49.2)$ & $32(50.8)$ & 1 & $\mathrm{I}$ \\
\hline \multicolumn{5}{|c|}{ Exclusive and immediate breastfeeding within I hour } \\
\hline Yes & $107(78.1)$ & $30(21.9)$ & $0.33(0.19-0.57)$ & $0.14(0.06-0.29)^{* * *}$ \\
\hline No & $75(54.3)$ & $63(45.7)$ & 1 & $\mathrm{I}$ \\
\hline \multicolumn{5}{|l|}{ UTI/STI } \\
\hline Yes & $20(43.5)$ & $26(56.5)$ & $3.14(1.64-6.0 I)$ & $1.12(0.39-3.25)$ \\
\hline No & $162(70.7)$ & $67(29.3)$ & $\mathrm{I}$ & $\mathrm{I}$ \\
\hline \multicolumn{5}{|l|}{ PROM } \\
\hline Yes & $24(52.2)$ & $22(47.8)$ & $2.04(1.07-3.88)$ & $1.85(0.42-8.08)$ \\
\hline No & $158(69)$ & $7 I(3 I)$ & $\mathrm{I}$ & 1 \\
\hline \multicolumn{5}{|c|}{ Neonate cries at birth } \\
\hline Yes & $149(7 \mid .3)$ & $60(28.7 I)$ & $0.40(0.23-0.7 I)$ & $0.52(0.17-1.62)$ \\
\hline No & $33(50)$ & $33(50)$ & $\mathrm{I}$ & 1 \\
\hline \multicolumn{5}{|c|}{ Put on KMC within I hour } \\
\hline Yes & $163(7 \mid .2)$ & $66(28.8)$ & $0.29(0.15-0.55)$ & $0.06(0.14-0.24)^{* * *}$ \\
\hline No & $19(41.3)$ & $27(58.7)$ & $\mathrm{I}$ & 1 \\
\hline \multicolumn{5}{|c|}{ Age of the neonate (days) } \\
\hline $0-7$ & $109(59.6)$ & $74(40.4)$ & $2.61(1.45-4.68)$ & $2.19(1.01-4.79)^{* *}$ \\
\hline $8-28$ & $73(79.3)$ & $19(20.7)$ & $\mathrm{I}$ & $\mathrm{I}$ \\
\hline \multicolumn{5}{|c|}{ Apgar score at fifth minute } \\
\hline$<7$ & $29(90.6)$ & $3(9.4)$ & I & I \\
\hline$\geq 7$ & $153(63)$ & $90(37)$ & $5.69(1.68-19.20)$ & $3.07(0.68-13.92)$ \\
\hline
\end{tabular}

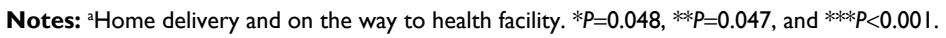

Abbreviations: KMC, kangaroo mother care; PROM, premature rupture of membrane; STI, sexually transmitted infection; UTI, urinary tract infection.

breastfeeding and KMC for mothers during postnatal and antenatal care services. Using Information Education Communication/Behavior Change Communication materials (posters, flip charts, wall paintings, manuals, brushers, and pamphlets) focused on breastfeeding and KMC to mobilize and sensitize the community. In addition, it should be recommended that the healthcare providers decrease multiple per digital vaginal examination as not indicated should better to be promoted. The other researchers do further investigation to identify other factors by using other tools and other study designs.

\section{Data sharing statement}

The data will not be shared in order to preserve participant anonymity.

\section{Acknowledgments}

Our unreserved thank goes to Arba Minch University for financial assistance. We would like to forward our deepest appreciation and thanks to the administrative bodies and healthcare providers in NICU of hospitals at Wolaita Sodo Town, data collectors, and study participants. Last but not least, we would like to say thank you to all the people who supported the study directly or indirectly. Arba Minch University, College of Medicine and Health and Sciences funded us for the data collection and stationary materials.

\section{Author contributions}

AM designed the study, was involved in data collection, did analysis and interpretation of the results, drafted the paper, and participated in preparing all versions of the manuscript. TW, SS, AB, AM, GS, GH, EA, and TT assisted in the design and proposal development, monitored data collection, assisted during analysis, and revised subsequent drafts of the paper. All authors contributed toward data analysis, drafting and critically revising the paper, gave final approval of the version to be published, and agreed to be accountable for all aspects of the work. 


\section{Disclosure}

The authors report no conflicts of interest in this work.

\section{References}

1. Edwards MS, Baker CJ. Sepsis in the newborn. In: Gershon AA, Hotez PJ, Katz SL, editors. Krugman's Infectious Diseases of Children. Philadelphia, PA: Mosby; 2004:545.

2. Warf BC, Alkire BC, Bhai S, et al. Costs and benefits of neurosurgical intervention for infant hydrocephalus in sub-Saharan Africa. J Neurosurg Pediatr. 2011;90(2):509-521.

3. Seale AC, Blencowe H, Zaidi A, et al. Neonatal severe bacterial infection impairment estimates in South Asia, sub-Saharan Africa, and Latin America for 2010. Pediatr Res. 2013;74(S1):73-85.

4. Fleischmann-Struzek C, Goldfarb DM, Schlattmann P, Schlapbach LJ, Reinhart K, Kissoon N. The global burden of paediatric and neonatal sepsis: a systematic review. Lancet Respir Med. 2018;6(3): 223-230.

5. Wu JH, Chen CY, Tsao PN, Hsieh WS, Chou HC. Neonatal sepsis: a 6-year analysis in a neonatal care unit in Taiwan. Pediatr Neonatol. 2009;50(3):88-95.

6. UNICEF, WHO, The World Bank, and The United Nations. Levels and Trends in Child Mortality. New York, NY: UNICEF; 2011.

7. GSA and WHO. World sepsis day 2017 - preventable maternal and neonatal sepsis a critical priority for WHO and Global Sepsis Alliance. Available from: https://static1.squarespace. com/static/58a7025b8419c215b30b2df3/t/59b1b9d52994caee6 bc0eba7/1504819673100/Press_Release_WSD_WSC_English_ Letterhead+(PDF).pdf. Accessed July 26, 2018.

8. Ranjeva SL, Warf BC, Schiff SJ. Economic burden of neonatal sepsis in sub-Saharan Africa. BMJ Glob Health. 2018;3(1):e000347.

9. Ferreira RC, Mello RR, Silva KS. Neonatal sepsis as a risk factor for neurodevelopmental changes in preterm infants with very low birth weight. J Pediatr (Rio J). 2014;90(3):293-299.

10. UNICEF. Ethiopia - health maternal health brief; 2014. Available from: www.unicef.org/ethiopia/health.html. Accessed June 28, 2018.

11. Berhanu D, Avan BI. Community Based Newborn Care Baseline Survey Report Ethiopia, October 2014. Project Report. London School of Hygiene \& Tropical Medicine; 2014. Available at: https://ideas.1shtm. ac.uk/report/community-based-newborn-care-baseline-survey-reportethiopia-october-2014/. Accessed July 26, 2018.

12. Klein JO, Remington JS. Current concepts of infection of the fetus and newborn infant. In: Remington J, Klein J, editors. Infectious Diseases of the Fetus and Newborn. Philadelphia, PA: WB Saunders; 2000. View at Google Scholar Egyptian Neonatal Network (EGNN), 2010;1-24.

13. The World Bank. World Development Indicators 2013. Washington, DC: The World Bank; 2013.

14. Central Statistical Agency (CSA) (Ethiopia) and ICF. Ethiopia Demographic and Health Survey 2016: Key Indicators Report. Addis Ababa, Ethiopia, and Rockville, MD: CSA and ICF; 2016.

15. Eman M, El-Din RS, Mohamed M, El-Sokkary A, Bassiouny MR, Hassan R. Epidemiology of neonatal sepsis and implicated pathogens: a study from Egypt. BioMed Res Int. 2015;2015:509484.
16. Tewabe T, Mohammed S, Tilahun Y, et al. Clinical outcome and risk factors of neonatal sepsis among neonates in Felege Hiwot referral hospital, Bahir Dar, Amhara regional state, North West Ethiopia 2016: a retrospective chart review. BMC Res Notes. 2017;10(1):265.

17. Leal YA, Álvarez-Nemegyei J, Velázquez JR, et al. Risk factors and prognosis for neonatal sepsis in southeastern Mexico: analysis of a four-year historic cohort follow-up. BMC Pregnancy Childbirth. 2012;12(1):1471-2393.

18. Medhat H, Khashana A, El kalioby M. Incidence of neonatal infection in South Sinai, Egypt. Int J Infect. 2017;4(1):e36615.

19. Mhada TV, Fredrick F, Matee MI, Massawe A. Neonatal sepsis at Muhimbili National Hospital, Dar es Salaam, Tanzania; aetiology, antimicrobial sensitivity pattern and clinical outcome. BMC Public Health. 2012;12(1):904

20. Manji, K. Situation Analysis of Newborn Health in Tanzania: Current Situation, Existing Plans and Strategic Next Steps for Newborn Health. Dar es Salaam, Tanzania: Ministry of Health and Social Welfare, Save the Children; 2009

21. Jabiri A, Wella HL, Semiono A, Saria A, Protas J. Prevalence and factors associated with neonatal sepsis among neonates in Temeke and Mwananyamala hospitals in Dar es Salaam, Tanzania. Tanzan J Health Res. 2016;18(4):1-7.

22. Kayange N, Kamugisha E, Mwizamholya DL, Jeremiah S, Mshana SE. Predictors of positive blood culture and deaths among neonates with suspected neonatal sepsis in a tertiary Hospital, Mwanza-Tanzania. BMC Pediatr. 2010;10(1):39-42.

23. Mersha A. Mother's level of knowledge on neonatal danger signs and its predictors in Chencha District, Southern Ethiopia. Am J Nurs Sci. 2017;6(5):426-432.

24. World Medical Association. World Medical Association Declaration of Helsinki ethical principles for medical research involving human subjects. JAMA. 2013;310(20):2191-2194.

25. Siakwa M, Kpikpitse D, Mupepi S, Semuatu M. Neonatal sepsis in rural Ghana: a case control study of risk factors in a birth cohort. Int J Res Med Sci. 2014;4(5):77-88.

26. Gebremedhin D, Berhe H, Gebrekirstos K. Risk factors for neonatal sepsis in public hospitals of Mekelle City, North Ethiopia, 2015: unmatched case control study. PLoS One. 2016;11(5):e0154798.

27. Lawn JE, Mwansa-Kambafwile J, Horta BL, Barros FC, Cousens S. "Kangaroo mother care" to prevent neonatal deaths due to preterm birth complications. Int J Epidemiol. 2010;39(Suppl 1): i144-i154.

28. Boundy EO, Dastjerdi R, Spiegelman D, et al. Kangaroo mother care and neonatal outcomes: a meta-analysis. Pediatrics. 2016;137(1): e20152238.

29. Shrivastava SR, Shrivastava PS, Ramasamy J. Utility of kangaroo mother care in preterm and low birthweight infants. S Afr Fam Pract. 2013;55(4):340-344

30. Mugadza G, Zvinavashe M, Gumbo FZ, Pedersen BS. Early breastfeeding initiation and incidence of neonatal sepsis in Chipinge district Zimbabwe. Int J Contemp Pediatrics. 2018;5(1):1-5.

31. Simonsen KA, Anderson-Berry AL, Delair SF, Davies HD. Early-onset neonatal sepsis. Clin Microbiol Rev. 2014;27(1):21-47.
Research and Reports in Neonatology

\section{Publish your work in this journal}

Research and Reports in Neonatology is an international, peer-reviewed, open access journal publishing original research, reports, editorials, reviews and commentaries on neonatal health. The manuscript management system is completely online and includes a very quick and fair peer-review system. Visit http://www.dovepress.com/testimonials.php to read real quotes from published authors. 